cherry-picked data, he presents a caricature of science that I do not recognize.

Why do social scientists find science so difficult to fathom? In my experience, most working scientists have a much better appreciation of the power and the limitations - of the scientific method than Collins is prepared to allow. Most have a robust understanding of Karl Popper's idea of falsification, of the impact of experimental error and the need for reproducibility in generating convincing evidence for a new hypothesis. Crucially, most would never assume that their findings represent an impregnable truth, or anything other than a work in progress.

Where I might agree with Collins is that science still struggles to make its authentic voice heard on many important issues that affect society. In part, that is because some of these issues, such as climate change, are complex and attract the attention of powerful vested interests. But it is not clear what social scientists aim to contribute to solving this problem.

What is needed is a broader channel of communication between scientists and society, both directly and through the news media, so that the real nature of the scientific process and the value of its output are made more accessible to citizens and policy-makers.

This is already emerging, independently of the musings of social scientists. Much of the initiative is coming from scientists, teachers, bloggers and other science communicators, with the openaccess movement providing an interesting new dimension.

Stephen Curry Blackett Laboratory, Imperial College,

London SW7 2AZ, UK

e-mail: s.curry@imperial.ac.uk

Readers are welcome to comment at $h t t p: / / t i n y u r l . c o m / a n y k w 6$.

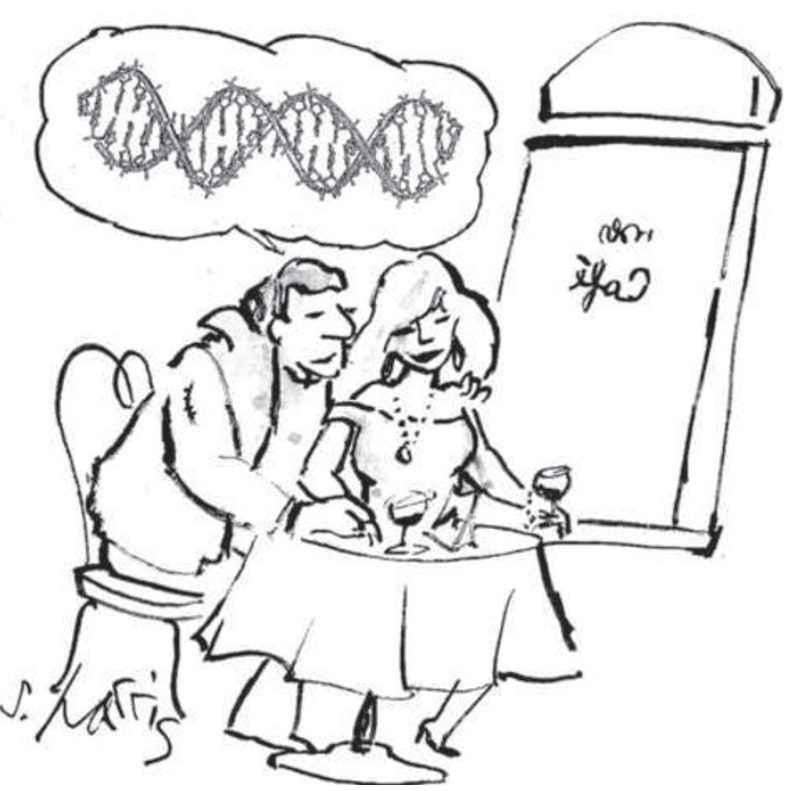

\section{For anyone who ever said there's no such thing as a poetic gene}

SIR - Art encoded in living cells has a long and illustrious history (J. Vallverdú Aesthethika 2, 2; 2006 and E. DaSilva Electron. J. Biotechnol. 7, 4; 2004). For obvious reasons, the focus has been to decode naturally existing biological codes (proteins or DNA) in the context of art, instead of coding new art into a biological system.

As Christian Bök proposes in Books \& Arts ('Poetry in the genes' Nature 458, 35; 2009), the emergence of de novo genesynthesis technology now makes the tools available to build poetry directly into coding genes.

In 2005, our organization made a gene encoding the first verse of the poem Tomten by Viktor Rydberg (50 words, or 800 base pairs). The verse was rewritten using the single-letter amino-acid code where $\mathrm{O}$ (no amino acid) was replaced by Q (glutamic acid) and spaces omitted. The protein sequence was backtranslated to DNA using the codon bias of reindeer (Rangifer tarandus). The gene was synthesized and cloned behind an Escherichia coli promoter in a pUC-derived vector. The construct was then lyophilized on filter paper and sent out as a Christmas card (see http://tinyurl.com/cxhy9a). The nucleotide and protein sequence of Tomten is available in GenBank, accession number EU600200.

To our knowledge, this is the first example of an organism that 'recites' poetry.

Claes Gustafsson DNA2.0 Inc., 1430 O'Brien Drive, Suite E, Menlo Park, California 94025, USA e-mail: cgustafsson@dna20.com

\section{Brain technologies raise unprecedented ethical challenges}

SIR - We share Jens Clausen's opinion, expressed in his Commentary 'Man, machine and in between' (Nature 457, 10801081; 2009), that brain-machine interfaces promise many benefits and should be pursued. However, we do not agree that these technologies pose similar ethical challenges to those already addressed. Some consequences may be unprecedented.

Imagine if insights from the field of cortical prosthetics in human and non-human primates were combined with research on bodily self-consciousness in humans. Signals recorded by multi-electrodes implanted in the motor cortex can already be used to control robotic arms and legs. Cognitive cortical prosthetics will allow the use of other cortical signals and regions for prosthesis control. Several research groups are investigating indications that the conscious experience of being in a body can be experimentally manipulated. The frontal and temporoparietal signals that seem to be involved encode fundamental aspects of the self, such as where humans experience themselves to be in space and which body they identify with (O. Blanke and T. Metzinger Trends Cogn. Sci. 13, 7-13; 2009). If research on cortical prosthetics and on the bodily self were applied to humans using braincontrolled prosthetic devices, there might be no clear answer to Clausen's question: which of them is responsible for involuntary acts?

It may sound like science fiction, but if human brain regions involved in bodily self-consciousness were to be monitored and manipulated online via a machine, then not only will the boundary between user and robot become unclear, but human identity may change, as such bodily signals are crucial for the self and the ' $I$ ' of conscious experience. Such consequences differ from those outlined by Clausen for deep brain stimulation and treatment with psychoactive drugs.

New links between cognitive neuroscience, engineering, brainmachine interfacing and medicine could lead to a generation of technologies that may not just blur the limits of human and machine, but fundamentally alter an individual's sense of self. We should welcome the machine to the brain, but should proceed with caution, given that such an addition could change the criteria for self and identity.

Olaf Blanke, Jane E. Aspell Laboratory of Cognitive Neuroscience, Ecole Polytechnique Fédérale de Lausanne, Lausanne, Switzerland e-mail: olaf.blanke@epfl.ch 